Para José Arrom

\title{
José Martí: el empleo artístico de la anécdota
}

Se ha observado a menudo que muchas obras de Martí, y en particular sus Versos sencillos, se basan en experiencias del propio poeta y en hechos anecdóticos; pero que estas obras siempre consiguen elevar estos episodios al plano del arte universal. ${ }^{1}$ Queda por precisarse suficientemente, sin embargo, cómo se logra este proceso, cómo puede Martí convertir hechos o recuerdos particulares en algo más amplio y duradero. Esto se puede hacer, a mi juicio, examinando detenidamente unas pocas obras importantes.

Un excelente ejemplo se nos suministra en el famoso poema IX de los Versos sencillos, el de la "Niña de Guatemala." Como se ha probado, la obra se basa en un episodio de la vida de Martí. Pero su valor para el lector reside más en las maneras con que el episodio se presenta y se transforma. José Arrom ha observado que el poema se desdobla en dos planos temporales, que se alternan, crean el efecto de endechas cantadas antifonalmente, $y$ se mezclan al final. ${ }^{3}$ También ha probado Arrom cómo ambos planos del poema se basan en romances tradicionales y cómo esto sirve para ligar la obra de Martí con los sentidos básicos de su tradición hispánica.

1 Véase Eugenio Florit, "Los versos de Martî", en José Martí, Versos (New York: Las Américas Pub. Co., 1962), p. 57; José Arrom, "Raíz popular en los 'Versos sencillos' de José Marti"', Certidumbre de Américá (La Habana: Anuario Bibliográfico Cubano, 1959), pp. 77-78; y Juan Marinello, José Marti, escritor americano (México: Ed. Grijalbo, 1958), pp. 141-142. Allen Phillips ha indicado la elevación de lo anecdótico en la prosa de Martí, en "Sobre una prosa de José Martí: 'El terremoto de Charleston'", Estudios y notas sobre literatura bis. panoamericana (México: Ed. Cultura, 1965), pp. 5-8.

2 Véase José María Izaguirre, "Martí en Guatemala", Revista Cubana, XXIX (1951-1952), pp. 332-342. Se trata de un ensayo escrito por un testigo, que cuenta en detalle el episodio de la relación entre Martí y María Granados.

3 Arrom, Certidumbre..., pp. 72-81. Debo mencionar también que mi lectura e interpretación de este poema debe mucho al profesor Arrom, en cuyos cursos lo leí primero hace muchos años, y con quien lo he discutido varias veces. 
Indagando más en los procedimientos observados por Arrom, podremos ver cómo Martí logra infundirle valor y permanencia al poema:

Quiero, a la sombra de un ala, Contar este cuento en flor:

La niña de Guatemala, La que se murió de amor.

Eran de lirios los ramos, $Y$ las orlas de reseda $Y$ de jazmín: la enterramos En una caja de seda.

...Ella dió al desmemoriado

Una almohadilla de olor:

El volvió, volvió casado:

Ella se murió de amor.

Iban cargándola en andas

Obispos y embajadores:

Detrás iba el pueblo en tandas

Todo cargado de flores.

...Ella, por volverlo a ver, Salió a verlo al mirador:

El volvió con su mujet:

Ella se murió de amor.

Como de bronce candente

Al beso de despedida

Era su frente jla frente

Que más he amado en mi vida!

...Se entró de tarde en el río,

La sacó muerta el doctor:

Dicen que murió de frío:

Yo sé que murió de amor.

Alli, en la bóveda helada, La pusieron en dos bancos: 
Besé su mano afilada, Besé sus zapatos blancos.

Callado, al oscurecer,

Me llamó el enterrador:

¡Nunca más he vuelto a ver

A la que murió de amor! *

Podemos establecer inmediatamente un contraste entre los dos grupos de estrofas en que se divide el poema. Uno de ellos, que consta de la primera, tercera, quinta y séptima estrofa, se refiere a un plano temporal más lejano: el proceso del enamoramiento y de la muerte. El otro grupo (las estrofas número dos, cuatro, seis y ocho) describe el entierro. ${ }^{5} \mathrm{Ca}$ da plano se percibe desde una perspectiva bien diferente. Al narrar el proceso más lejano en las estrofas impares, el protagonista parece adoptar un punto de vista objetivo y hasta frío. Las rimas agudas en or, la falta de encabalgamientos y el empleo frecuente de dos puntos cortan los versos y crean un efecto abrupto. La seca narración del episodio, sin matices ni detalles que caractericen a los personajes, parece objetivar demasiado el asunto. Varios rasgos estilísticos acentúan este tono seco de las estrofas impares: la escasez de adjetivos y el predominio de los sustantivos y los verbos; el empleo de verbos en el pretérito perfecto absoluto, que imparte un aire de finalidad abrupta a los hechos. ${ }^{6}$ La escena de la ofrenda de la almohadilla, que pudiera haber parecido romántica en sí, se presenta con tal rapidez, y va seguida tan inmediatamente de la vuelta y de la muerte, que parece fría. La rapidez con la cual se suceden todos los hechos en estas estrofas subraya el aparente tono de objetividad. Hasta la alusión a la "muerte de amor" parece cobrar, en el contexto de estas estrofas, una sequedad que no concuerda con la idea romántica a la que alude. Si leyésemos sólo estas estrofas impares, tendriamos que confesar que toman una perspectiva terriblemente desprovista de pasión. $Y$ aun tomando en cuenta la sugerencia de Gabriela Mistral, de que el tono seco se debe a un deliberado esfuerzo de Martí de no exagerar su dolor, no estamos completamente satisfechos con esta perspectiva. ${ }^{7}$

4 José Martí, Poesías completas (Madrid: Ed. Aguilar, 1953), pp. 90-91.

5 Arrom (pp. 73-74) ha descrito esta división.

6 Véase la caracterización de estos tiempos verbales en Samuel Gili y Gaya, Curso superior de sintaxis española (Barcelona: Ediciones Spes, 1955), pp. 132$134,138-140$ y $142-143$.

7 Gabriela Mistral, "Los 'Versos sencillos' de José Martí", en Martí, Versos sencillos (La Habana: Secretaría de Educación, 1939), pp. 28-30. La misma Gabriela Mistral no parece del todo satisfecha con la explicación. Arrom (p. 73) explica el ritmo de canción del poema notando su procedencia tradicional. 
El otro grupo de estrofas, en cambio, subraya aspectos sensoriales $y$ emotivos. Encontramos en las estrofas pares frecuentes encabalgamientos, que nos obligan a una lectura más seguida. Se acentúa aquí la descripción del cortejo funeral, y no la narración de hechos; se suscitan diversas sensaciones mediante las alusiones a las flores, a la seda. Los verbos empleados aparecen en el pretérito imperfecto, que subraya la descripción y la duración de los episodios, no su finalidad. En la cuarta estrofa, la alusión a los obispos y los embajadores evoca un grandioso entierro romántico. En la segunda estrofa el protagonista ya se incluye a sí en el cortejo, y en la sexta habla directamente de su amor a la muchacha. (Recordaremos que en el otro grupo de estrofas todo aparecía en tercera persona, y el protagonista era sencillamente "el desmemoriado.") La exclamación en la sexta estrofa, y la alusión romántica a la "bóveda helada" en la octava intensifican el tono romántico. Este grupo de estrofas, por lo tanto, muestra una actitud mucho más emotiva y comprometida por parte del protagonista. Si las estrofas impares parecian reducir la tragedia de la "niña de Guatemala" a una objetividad excesiva, las pares parecen recalcar, tal vez demasiado, la índole romántica del episodio y los sentimientos personales del protagonista ante los hechos. Hasta podemos comprobar que en las estrofas pares Martí ha transformado la historia actual para subrayar lo romántico; aunque en la actualidad él nunca correspondió al amor de María Granados, en la sexta estrofa hace que el protagonista declare su amor por "la niña". ${ }^{8}$ Múltiples recursos, en suma, ayudan a destacar la tragedia romántica.

Hemos visto, pues, cómo los dos grupos de estrofas presentan dos puntos de vista opuestos ante una realidad del pasado. Estos dos puntos de vista representan, en efecto, dos extremos de las actitudes que pudieran tomarse ante una experiencia recordada: la observación y el distanciamiento por una parte, la intensa reacción emotiva por otra. El protagonista de este poema oscila entre ambos extremos, alternando las estrofas que los representan. Asi parece estar tratando de hallar una resolución satisfactoria, una visión que se sobreponga a las limitaciones de cada actitud extrema.

A medida que se desarrolla la obra, podemos observar, en efecto, una gradual unión de los dos puntos de vista. La séptima estrofa, por ejemplo, parece pertenecer al grupo "objetivo," y muestra la misma condensación de las otras estrofas impares. Pero aquí esta condensación sirve

8 Izaguirre (pp. 337-338) explica en detalle cómo Martí, notando el enamoramiento de la chica, deja de visitar la casa de su padre. La transformación del episodio en el poema es un excelente ejemplo del modo en que el poeta Marti altera la realidad anecdótica con fines artísticos. 
para expresar dramáticamente, en el último verso, la creencia personal del protagonista en la trágica muerte de amor. ${ }^{9}$ La forma escueta subraya aquí una actitud romántica. La octava estrofa pertenece al grupo "emotivo"; pero revela también la observación minuciosa de detalles objetivos. Parece como si el protagonista lograse ahora fundir sus dos actitudes anteriores en una sola visión coherente. Esto ocurre precisamente cuando, al final del poema, se funden los dos planos temporales: la narración del episodio amoroso y la descripción del cortejo, para desembocar ambos en la escena ante la tumba.

Leyendo las estrofas alternadas de este poema, hemos sentido la tensión entre los dos planos temporales y los dos puntos de vista opuestos. Y a medida que el protagonista, a fuerza de elaborar perspectivas, ha llegado a desarrollar una actitud integradora y equilibrada, también hemos llegado a sentir la integración satisfactoria de una actitud romántica con otra objetiva. El poema nos impresiona, precisamente, porque encarna este proceso de dos perspectivas parciales que finalmente quedan resueltas. El episodio particular que trata ha servido principalmente para dramatizar este proceso y este tema. Mediante una realidad particular elaborada artísticamente, Martí ha logrado crear una obra que nos hace sentir vívidamente un amplio y constante problema de nuestra existencia: el de desarrollar nuestra actitud ante las experiencias de la vida, integrando las diversas reacciones que éstas engendran en nosotros.

Importa notar también que el protagonista llega a su resolución al recrear su experiencia en las formas del verso - de un verso cuidadosamente organizado y sujeto a formas tradicionales. La poesía ha sido su modo de resolver sus experiencias humanas. El poema nos hace entrever aquí el tema de la poesía como manera de aclarar y universalizar los valores de la realidad. Recordando que para Martí ala se liga con la inspiración poética, podemos ver que este poema, escrito "a la sombra de un ala", nos muestra cómo la poesía resuelve experiencias humanas. ${ }^{10}$

En el poema de "la niña de Guatemala", hemos visto el empleo de varios procedimientos artísticos que convierten lo que hubiera podido ser la narración de un episodio anecdótico en un poema de amplio alcance. De modo parecido, Martí, en el poema $\mathrm{X}$ de los Versos sencillos, convierte la descripción de una bailarina $\mathrm{y}$ de un baile en una obra acerca de lo ordinario, de la belleza y del arte. El poema trata un episodio que probablemente le sucedió a Martí en Nueva York; al decir que entra a

9 Arrom ha notado este efecto (p. 78).

10 Ivan Schulman ha comentado este valor de la palabra ala en Simbolo y color en la obra de José Martí (Madrid: Ed. Gredos, 1960), pp. 131-14́. 
ver el baile porque han quitado la bandera de España, el protagonista toma la actitud de Martí, patriota y revolucionario cubano. Pero el estilo y la estructura de la obra amplían su significado.

La obra tiene una estructura circular: empieza con los versos "El alma trémula y sola/ Padece al anochecer"; acaba "iVuelve, fosca, a su rincón/ El alma trémula y sola!" Así se subraya que el baile presenciado por el protagonista representa un intervalo brillante, que saca al hombre momentáneamente de su existencia solitaria y dolorosa. La ausencia de la bandera de España, y las alusiones a la bailarina como "divina" más bien que "gallega", hacen que esta mujer trascienda las categorías particulares de la nacionalidad y la política, y que represente algo más valioso y universal. Su baile, en efecto, viene a configurar una belleza superior, la cual le permite al protagonista remontarse más allá de su existencia ordinaria.

Esto se comprueba estudiando la descripción que forma la parte central de poema:

Se ve, de paso, la ceja,

Ceja de mora traidora:

Y la mirada, de mora:

$Y$ como nieve la oreja.

Preludian, bajan la luz, $Y$ sale en bata y mantón,

La virgen de la Asunción

Bailando un baile andaluz.

Alza, retando, la frente;

Crúzase al hombro la manta:

En arco el brazo levanta:

Mueve despacio el pie ardiente.

Repica con los tacones

El tablado zalamera.

Como si la tabla fuera

Tablado de corazones.

$\mathrm{Y}$ va el convite creciendo

En las llamas de sus ojos,

$Y$ el manto de flecos rojos

Se va en el aire meciendo. 
Súbito, de un salto arranca:

Húrtase, se quiebra, gira:

Abre en dos la cachemira,

Ofrece la bata blanca.

El cuerpo cede y ondea;

La boca abierta provoca;

Es una rosa la boca;

Lentamente taconea.

Recoge, de un débil giro,

El manto de flecos rojos:

Se va, cerrando los ojos,

Se va, como en un suspiro... ${ }^{1 \mathrm{~T}}$

Al otorgarle a la bailarina rasgos y de "mora traidora" y de la Virgen, Martí la hace representar la inocencia por un lado, el atractivo sexual por otro. Así la convierte en un compendio de diversos atractivos femeninos. (También pudiera verse esta mezcla de rasgos en el repetido empleo de los colores blanco y rojo, evocadores de la pasión y de la inocencia.)

El baile mismo se describe con creciente intensidad: se nos presentan los movimientos cada vez más rápidos de la bailarina, y la caracterización cada vez más intensa de estos movimientos por parte del protagonista. La sexta estrofa citada representa el clímax del baile: de pronto todo movimiento cesa, y el tiempo parece detenerse. Así la bailarina y su baile absorben cada vez más al protagonista, lo elevan cada vez más por encima de su soledad cotidiana. Pero tal estado no puede durar: después del momento central de la sexta estrofa citada, se reanuda el movimiento del baile, la intensidad disminuye, y ocurre la lenta, desvaneciente salida de la bailarina. El poema acaba con la vuelta del protagonista a su mundo ordinario, con sólo el recuerdo de la belleza presenciada:

Baila muy bien la española,

Es blanco y rojo el mantón:

¡Vuelve, fosca, a su rincón

El alma trémula y sola! ${ }^{12}$

11 Marti, Poesias completas, pp. 91-92.

12 Ibid., p. 93. 
La estructura circular (ascendiente y descendiente) de la obra, la caracterización de la bailarina, y los otros rasgos observados nos hacen ver a la bailarina y a su baile como un episodio de gran belleza que ofrece un breve momento de luz en medio de las tinieblas del mundo ordinario. No podemos decir que la bailarina sea un "símbolo"; no representa conceptualmente la belleza. Pero tal como se nos presenta, y sin perder sus características de personaje particular de un episodio concreto, viene a suscitar el tema general de una belleza que irrumpe momentáneamente y que nos eleva por encima de lo cotidiano. Pudiera hasta decirse que su arte del baile nos hace pensar en el arte en general, y en la poesía, como maneras de alcanzar una visión trascendente.

En ambos de los poemas comentados, Martí se vale de episodios muy particulares, de experiencias propias. Además, parece subrayar lo particular de estos episodios mediante alusiones como la de la bandera y las de Guatemala y del cortejo. Dado el hecho de que cada poema apunta a valores más amplios, esto no puede deberse a un deseo de recrearse en la anécdota misma. Pero sí sirve para hacernos sentir que los temas universales de cada obra no están desligados de la vida real particular. Así las obras se salvan de la vaguedad y de la excesiva abstracción, y sitúan sus significados amplios dentro de lo concreto de la vida humana. ${ }^{13}$

Otros poemas de Versos sencillos también se valen de episodios aparentemente anecdóticos para captar significados más amplios. El poema VII, por ejemplo, trata del respeto que Martí le tiene a Aragón, y de sus recuerdos de aquella tierra ("Que allí tuve un buen amigo,/ Que allí quise a una mujer," Poesías completas, pág. 88). Pero mediante la evocación de Aragón, se desarrolla en el poema el tema de la dignidad del hombre libre que defiende su libertad, y también el de la hermandad de todos los hombres libres. De manera más concisa el poema XII, que describe un viaje en un bote, nos hace sentir el horror de la presencia de algo impuro alrededor de nosotros:

En el bote iba remando

Por el lago seductor,

Con el sol que era oro puro

Y en el alma más de un sol.

13 Sobre el modo en que un buen poema es a la vez concreto y universal, véase William Wimsatt, The Verbal Icon, $2^{\mathrm{a}} \mathrm{ed}$. (New York: The Noonday Press, 1958), pp. 69-83, y Hateful Contraries (Lexington: Univ. of Kentucky Press, 1965), pp. 228-229. 
$Y$ a mis pies vi de repente,

Ofendido del hedor,

Un pez muerto, un pez hediondo

En el bote remador. ${ }^{14}$

Aquí todo se reduce a un cuadro brevísimo. La primera estrofa, al subrayar lo ideal de la escena, nos hace sentir que se trata de un viaje metafórico más que anecdótico. En este sentido, el descubrimiento del pez hediondo sugiere el descubrimiento de lo mezquino cuando pensamos habernos elevado a un mundo superior. Pero este tema, que bien pudiera haber parecido abstracto e irreal, cobra vitalidad mediante la imagen tan común, casi pedestre, del pez; así el tema amplio queda relacionado con nuestra existencia cotidiana, y reflejado en el mundo particular en que vivimos. Aunque aquí no se trate tal vez de un episodio anecdótico, este poema, como los que vimos antes, se vale de un hecho muy común para concretar un tema algo abstracto.

Parecido al poema XII es el XVIII (Poesías completas, pág. 97), en el cual la superficialidad se representa mediante la imagen de una mujer que rechaza un alfiler de oro para aceptar uno de plata y similor. En otros poemas, el episodio descrito puede no parecer común ni anecdótico, pero se presenta mediante acciones y frases comunes. Así, en el poema XI (pág. 93), un esqueleto que se liga con la conciencia artistica . y humana del poeta se encarna en un paje que le "cuida" y le "gruñe". Podemos ver, por lo tanto, que de diversos modos Martí emplea lo anecdótico y lo cotidiano en Versos sencillos para dar expresión lograda a significados amplios. El empleo de los detalles particulares, y la transformación de estos detalles mediante los recursos artísticos que hemos observado, le han permitido a Martí forjar poemas de primer orden, significativos y concretos al mismo tiempo.

Esta manera de valerse de lo anecdótico, tan aparente en Versos sencillos, puede encontrarse a veces en otros poemas de Marti. Ya en "El padre suizo," de Versos libres (Poesías completas, pp. 130-131), se cita la noticia de un periódico describiendo cómo un hombre se mató a sí mismo y a sus tres hijos. Luego, a base de la noticia, se desarrolla un poema acerca de la lucha indómita del hombre contra la tiranía. Y en "Amor de ciudad grande," también de Versos libres (pp. 142-144), las alusiones a los cinismos de la vida neoyorkina, vista de cerca por Martí, sirven para presentar el tema de la corrupción humana en general. Aun-

14 Martí, Poesiass completas, p. 94. 
que estos poemas carezcan, tal vez, del dominio formal y del impacto de los Versos sencillos, revelan ya el interés de Martí en utilizar lo anecdótico como vehículo de significados de mayor importe.

También encontraremos este interés en la prosa de Martí. "El terremoto de Charleston," por ejemplo, parece a primera vista un reportaje. Se escribió en Nueva York el 10 de septiembre de 1886, unos once días después del terremoto, y se publicó en La Nación de Buenos Aires en octubre del mismo año. ${ }^{15}$ Como Allen Phillips ha indicado, Martí pudo obtener numerosos detalles acerca de la catástrofe de los diarios de Nueva York; luego los compuso y organizó para crear una visión poética total. ${ }^{16}$ Phillips ha indicado que Martí centra la obra en el tema de la lucha del Hombre con los obstáculos de la vida, y que imparte valores casi alegóricos al terremoto y a los personajes. ${ }^{17}$ Esto ya indica la transformación artística de lo anecdótico con fines universales.

Importa estudiar los recursos estilísticos y estructurales que se emplean en esta obra, para ver cómo logra Martí unir lo particular con lo universal, y los efectos que obtiene. Después de anunciar el terremoto, Martí describe la ciudad antes de la catástrofe mediante una serie de imágenes del orden:

Los blancos vencidos y los negros bien hallados viven allí después de la guerra en lánguida concordia; allí no se caen las hojas de los árboles;... Las calles van derechas a los dos ríos; borda la población una alameda que se levanta sobre el agua;... en la calle de King se comercia; la de Meeting ostenta hoteles ricos; viven los negros parleros y apretados en un barrio populoso; y el resto de la ciudad es de residencias bellas. . ${ }^{18}$

A primera vista, todo parece muy atrayente. Pero ¿no es demasiado perfecto para encajar en nuestro mundo ? ${ }^{19}$ Una ciudad del Sur de los Estados Unidos en la cual, pocos años después de la Guerra Civil, blan. cos y negros viven en concordia parece un milagro. Un sitio donde los árboles no pierden las hojas es excepcional. La descripción de las calles y de los bartios, que subraya el orden geométrico y la felicidad de todos

15 Véase José Martí, "El terremoto de Charleston", Obras completas, tomo 1 (La Habana: Ed. Lex, 1953), pp. 1741-1751.

16 Véase Phillips, pp. 6*8.

17 Ibid., p. 11. Phillips también comenta perspicazmente el empleo de la metáfora para concretar efectos etéreos en la obra; el uso de descripciones sensoriales, del adjetivo, y de efectos rítmicos; el manejo logrado de la narración y la compenetración de lo matefórico con lo narrativo (pp. 7-8 y 14-17).

18 Martí, Obras completas, I, pp. 1741-1742.

19 Phillips (p. 13) ha comentado el contraste entre el orden y el caos. 
los sectores, ricos y pobres, contradice lo que sabemos acerca de las ciudades de nuestro mundo. La separación tan feliz de blancos y negros también parece un bien ilusorio. Destacando la excelencia nítida de esta ciudad, subrayando su exacta perfección mediante frases paralelas, Martí al mismo tiempo nos hace sentir que el orden de Charleston es tan extremo que no cabe en nuestro mundo real.

Cuando este orden se desbarata en el terremoto, por lo tanto, su pérdida nos parece casi inevitable. Al describir los rieles torcidos del ferrocartil y las torres caídas, Martí opone el desorden geométrico al orden geométrico anterior; al hacer que los blancos y los negros vivan ahora juntos, contrapone un mundo social flexible a la rigidez anterior; al escribir que "ocho millones de pesos rodaron en polvo en veinticinco segundos", indica el desbarato de las proporciones numéricas. ${ }^{20} \mathrm{La}$ vida después del terremoto, tan dramáticamente contrastada a la anterior, parece sin embargo mucho más próxima a la que ocurre en nuestro mundo; aun sin terremotos, las ciudades que conocemos revelan imperfecciones geométricas y pérdidas económicas.

Luego observa Martí que estas desdichas "hay que verlas desde lo alto de los cielos," y las define como "el ajuste del suelo visible sobre sus entrañas encogidas, indispensable para el equilibrio de la creación". ${ }^{21}$ Dado el contrate que se ha establecido, esta frase hay que leerla metafóricamente. Nos hace sentir que el mundo en el cual vivimos no puede existir en un orden perfecto, y que cierto desequilibrio es tal vez indispensable para el desarrollo de nuestras vidas. Esto se comprueba en el cuadro del hombre que se ofrece después:

No es el hombre más que una de esas burbujas resplandecientes que danzan a tumbos ciegos en un rayo de sol; ; pobre guerrero del aire, recamado de oro, siempre lanzado a tierra por un enemigo que no ve, siempre levantándose aturdido del golpe, pronto a la nueva pelea...! ¡Pero siente que sube como la burbuja por el rayo de sol...! ${ }^{22}$

Aquí se aclara un doble concepto central de la obra: la fragilidad del hombre, pero también el valor y la dignidad que adquiere luchando en contra de los desastres que le oprimen, y buscando constantemente el orden. La imagen del hombre como burbuja se repite en la página final del relato, destacando la importancia de este tema.

20 Véase Martí, Obras completas, I, p. 1742.

21 Ibrid., p. 1742.

22 Ibid., pp. 1742-1743. 
Esta primera sección del relato (pp. 1741-1743 de las Obras comple. tas, tomo I) es una versión en pequeño de toda la obra. Después de contrastar el orden imposible de la ciudad con el caos posterior, y después de indicar que al luchar contra éste cobra el Hombre su valor, Martí vuelve en la sección siguiente al cuadro de la ciudad antes del terremoto. $Y$ ahora desenvuelve, más despacio y con más complejidad, el mismo contraste y la misma visión del Hombre. La contraposición del orden con el caos se desarrolla ahora minuciosamente, mediante tres viñetas; los impresores, los devotos, y la gente que duerme en sus casas representan el ritmo armónico de la ciudad. De pronto sobreviene el terremoto y las mismas tres viñetas se repiten, convertidas ahora en imágenes del caos: "sus letras sobre las cajas dejaron caer los impresores, con sus casullas huían los clérigos, sin ropas se lanzan a las calles las mujeres olvidadas de sus hijos..."23 Los paralelos y los contrastes destacan el cambio de vida efectuado.

Sigue una serie de frases cortas, separadas por medio de dos puntos, que reflejan el desorden; el estilo fragmentario se ajusta al tema. El cuadro que se of rece parece al principio rebajar al Hombre: los personajes gritan como animales y se olvidan de sus familias, sólo unos pocos luchan contra el terror. La dignidad de la ciudad perfecta parece haber desaparecido.

Pero luego se nos presentan viñetas más positivas: gentes que preparan camas de paja, que duermen a un niño, que se ocupan de los muertos y de los heridos; niños que acaban de nacer, indicando la continuidad de la vida; un hombre orgulloso de la preservación de la casa de la justicia (Obras completas, I, pp. 1744-1746). La tierra sigue inhóspita, eI suelo está cubierto de grietas, el agua sabe a azufre; faltan los instrumentos de la civilización, y el ferrocarril no puede llegar a Charleston (pp. 1746-1747). Pero los hombres hacen de los árboles casas, y allí se comunican entre sí y rezan a Dios. Desprovistos de los auxilios de la civilización, logran sin embargo reestablecer una forma primitiva de vida social, ayudándose unos a otros y practicando su religión. Así se nos hace sentir el esfuerzo del Hombre de elevarse. $Y$ este esfuerzo parece más legítimo, más sincero y más importante que el orden geométrico y algo mecánico que regía en Charleston antes del terremoto. El orden de la imprenta o de los ritos de la iglesia descritos antes resultó algo externo, y se desbarató fácilmente; la ayuda mutua y la oración que surgen ahora otorgan mayor valor y dignidad a los habitantes.

Martí luego desarrolla (pp. 1747-1750) un cuadro de los negros

23 Ibid., p. 1743. 
como seres naturales que empiezan a jugar un papel importante en esta época de vida primitiva. Phillips ha indicado que aquí se ve el interés de Martí en la dignidad de todo hombre, y su oposición al racismo. ${ }^{24}$ Pero en vista del tema de la obra, los negros son ante todo una imagen del ser humano más cercano a la naturaleza, que puede adaptarse mejor a un mundo desprovisto de los auxilios artificiosos de la técnica. Su religión, su Biblia y su Cristo muy personal vienen a representar la reli. gión y la bondad básica del hombre natural.

Al final del relato, el ferrocarril vuelve a Charleston, se reciben dineros para restaurar la ciudad, y parece volverse al orden inicial. Luego Marti vuelve a discutir la causa del terremoto: la ley de formación del suelo, que produjo un inevitable cataclismo. Así nos hace sentir, de nuevo, que el desequilibrio contemplado es parte íntegra del mundo nuestro. $Y$ que este desequilibrio, con todos sus efectos horrendos, le ofrece también al Hombre la oportunidad de luchar para enaltecer su dignidad, sus creencias, su humanidad. La descripción final de una madre cuidando a los dos gemelos nacidos durante el desastre subraya el sobrevivir y el triunfo del Hombre.

Charleston antes del terremoto parecía un paraíso terrenal: un mundo geométricamente ordenado, donde no había desequilibrios y donde el Hombre no tenía nada que hacer. Charleston después del terremoto parece un mundo después de la "caída", en el que el Hombre tiene que luchat contra los elementos y contra sus propios miedos e instintos, para man. tener sus valores y ganarse, por sí mismo, la dignidad. ${ }^{25}$

Sorprenden e impresionan las semejanzas que existen entre "El terremoto de Charleston" y los poemas comentados antes. En cada caso, la obra cobra valor al partir de lo anecdótico. Empieza situándonos en una realidad particular, irrepetible. Luego, cuando revela un tema amplio y casi etéreo (el del valor del Hombre, el de las perspectivas, el de la belleza), nos hace sentir que tal tema se encuentra dentro de lo concreto de nuestro mundo; y se salva de la excesiva abstracción.

Tal vez importe más aún subrayar cómo, en cada obra comentada, Martí le imparte al episodio anecdótico una estructura exacta. En "El terremoto" y en el poema IX, divide la realidad en dos elementos opuestos: las dos perspectivas del poema, los dos mundos del relato. En el

24 Phillips, pp. 9-10.

25 Pueden encontrarse varias otras obras en prosa de Martí que funcionan de modo parecido a "El terremoto". En "Historia de un proceso famoso (áspero verano)", Obras completas, I, pp. 1807-1813, el reportaje de un proceso of rece una visión de la corruptibilidad humana, y también del lado humano del hombre corrupto. 
poema X utiliza un esquema circular. En cada caso la estructura salta a los ojos del lector, le hace ver que el episodio se ha configurado artísticamente, y lo lleva directamente hacia un tema más amplio. La realidad particular y la estructura evidente se apoyan mutuamente para darnos una obra a la vez concreta y significativa. En cada caso, también, un cuidadoso empleo del estilo apoya la estructura de la obra, destaca los temas, y suscita la reacción personal del lector. (Piénsese en el efecto del cambio del estilo en los dos grupos de estrofas del poema \# IX.)

El estudio de estas obras nos ayuda a ver a Martí el escritor no como a un periodista ni como a un versificador de sus propias experiencias, sino más bien como a un gran artista creador, que logra elevar los elcmentos de la vida cotidiana a planos universales, y que logra traer visiones universales al nivel de nuestras experiencias humanas concretas. ${ }^{26}$

ANDREW P. DEBICKI

University of Kansas

26 El mismo Martí revela una gran conciencia de la necesidad de basar la poesia en lo concreto, y de luego remontarse a temas y valores duraderos. Vale citar sus propias palabras, tomadas aquí de Manuel Pedro González e Ivan Schulman, eds., José Martí, esquema ideológico (México: Ed. Cultura, 1961): "La poe. sía ha de tener la raíz en la tierra, y base de hecho real. Se desvanecen los castillos de nubes" (pág. 143.) "Y el arte nace de eso: de la impresión directa" (pág. 323.) "Todo el arte de escribir es concretar" (pág. 134.) "El que ajuste su pensamiento a su forma, como una hoja de espada a la vaina, ese tiene estilo" (pág. 124.) "El lenguaje ha de ser matemático, geométrico, escultórico. La idea ha de encajar exactamente en la frase, tan exactamente que no pueda quitarse nada de la frase sin quitar eso mismo de la idea" (pág. 131.) "Mi objeto es desembarazar del lenguaje inútil la poesía: hacerla duradera..." (pág. 166.) "Y ¡cómo duran los versos! ...El poeta unge con óleo de vida eterna los paisajes que pinta y los héroes que consagra" (pág. 324.)

Estas citas revelan clatamente el interés de Martí en combinar lo particular de la realidad con el empleo exacto de la forma para crear una obra a la vez inmediata y universal, y que por lo tanto durará y será asequible a los lectores del futuro. 